\title{
CONTAMINAÇÃo DE ÁGUAS SUBTERRÂNEAS POR PESTICIDAS: AVALIAÇÃo PRELIMINAR
}

\author{
Maria Lúcia Ribeiro e Carolina Lourencetti* \\ Centro Universitário de Araraquara, Rua Carlos Gomes, 1338, 14801-340 Araraquara - SP, Brasil \\ Sueli Yoshinaga Pereira \\ Instituto de Geociências, Universidade Estadual de Campinas, CP 6152, 13083-970 Campinas - SP, Brasil \\ Mary Rosa Rodrigues de Marchi \\ Instituto de Química, Universidade Estadual Paulista, CP 355, 14801-970 Araraquara - SP, Brasil
}

Recebido em 13/1/06; aceito em 17/7/06; publicado na web em 19/1/07

\begin{abstract}
GROUNDWATER CONTAMINATION BY PESTICIDES: PRELIMINARY EVALUATION. A discussion about groundwater contamination is presented in this work. Contamination by agricultural activity, more specifically by pesticides is emphasized. Indirect and direct estimates could be used to predict pesticide behavior in soil, and consequently, to evaluate the potential of groundwater contamination. These results could be applied to advise about the possibility of groundwater contamination by pesticides, and to provide subsidies for making decisions more quickly and efficiently.
\end{abstract}

Keywords: groundwater; pesticides; contamination.

\section{INTRODUÇÃO}

Os recursos hídricos agem como integradores dos processos biogeoquímicos de qualquer região. Sendo assim, quando pesticidas são aplicados, particularmente na agricultura, os recursos hídricos, sejam superficiais ou subterrâneos, são os principais destinos dos pesticidas. Programas de monitoramento ambiental, realizados por meio de estudos de campo bem planejados, são considerados por diversos autores como o melhor procedimento de avaliação, gerando informações que subsidiem ações para minimizar a poluição da água subterrânea ${ }^{1-4}$. Estes estudos podem ser realizados analisando-se diretamente a água e/ou o solo, uma vez que o potencial de contaminação da água subterrânea por pesticidas depende da mobilidade dos mesmos no solo. Devido ao grande número de princípios ativos utilizados na agricultura, as análises exigem métodos multi-resíduos eficientes e capazes de detectar limites máximos de resíduos estabelecidos por legislação (LMR) e concentrações consideradas de alerta para a saúde humana 5 . Outro fator importante é a limitação na interpretação dos resultados de monitoramento, tais como fator de diluição e repetibilidade na coleta das amostras em um mesmo ponto. Além desses fatores, estudos de monitoramento apresentam elevado custo e consomem muito tempo, devido ao grande número de análises que devem ser realizadas ${ }^{6}$. Quando estes dados não estão disponíveis, o que ocorre na maioria dos casos, outro caminho deve ser encontrado para simular a realidade, como a avaliação da mobilidade de pesticidas no solo. Neste sentido, essa avaliação pode envolver aproximações diretas, como estudos em campo ou laboratório, ou indiretas, como uso de modelos de avaliação do potencial de lixiviação dos pesticidas. Resultados gerados por essas investigações podem ser utilizados para determinar o potencial de mobilidade dos pesticidas e a possibilidade de contaminação das águas subterrâneas, assim como fornecer subsídios para planejamento e implantação de políticas públicas pelos órgãos governamentais.

*e-mail: carollourencetti@yahoo.com.br

\section{Água subterrânea: considerações gerais}

A hidrogeologia é a ciência que estuda as águas subterrâneas. De acordo com Domenico e Schwartz" " "hidrogeologia é o estudo das leis que governam o movimento das águas subterrâneas, as interações mecânicas, físicas e termais dessa água com o sólido poroso, e o transporte de energia, constituintes químicos e a matéria particulada pelo fluxo".

Em síntese, a água subterrânea faz parte de um processo dinâmico e interativo do ciclo hidrológico, pelo qual a água circula do oceano para a atmosfera e dessa para os continentes, de onde retorna, superficial e subterraneamente, ao oceano ${ }^{8}$.

A Figura 1 apresenta as inter-relações da água subterrânea com os vários sistemas existentes.

Ao atingir a zona saturada, abaixo da superfície freática, a água se movimenta de acordo com as condições das rochas hospedeiras. As rochas hospedeiras, saturadas, são aqüíferos se permitirem que

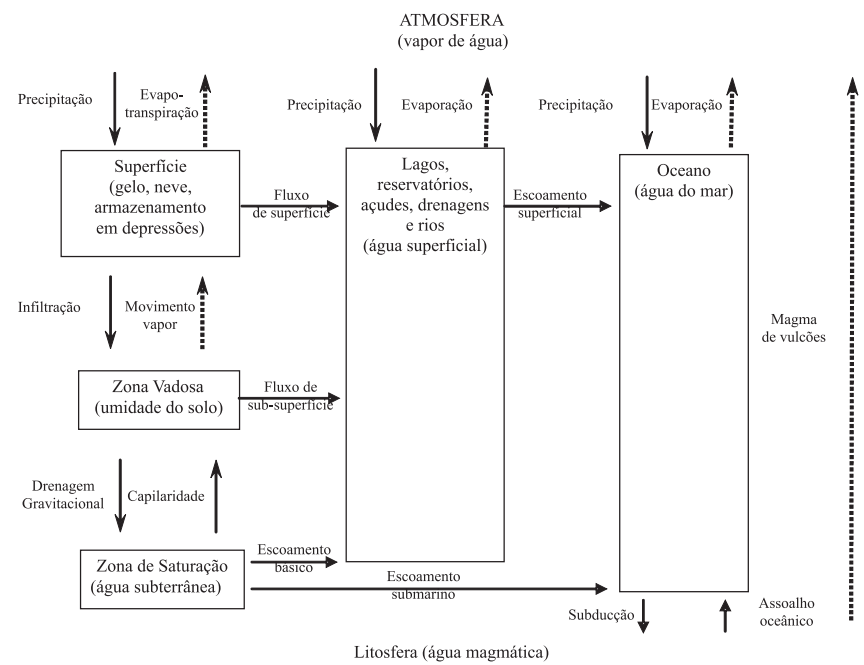

Figura 1. Ciclo hidrológico e as inter-relações entre os vários sistemas. Adaptado da ref. 9 
quantidades significativas de água se movimentem no seu interior em condições naturais ${ }^{8}$. Essas rochas podem ser encontradas sob várias condições, que as definem como livres, confinada, confinadas drenantes e suspensas, bem como de acordo com o tipo litológico, em poroso, fissural e cárstico (Figura 2).

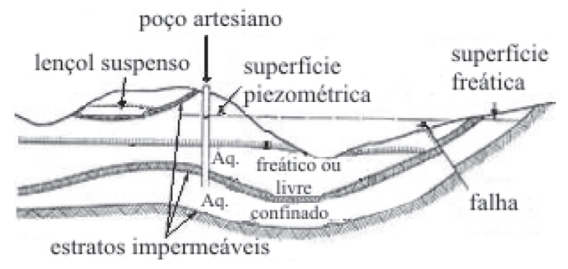

Figura 2. Formas e ocorrência da água subterrânea. Adaptada da ref. 10

A água que se infiltra e se torna subterrânea possui uma dinâmica própria e, de acordo com o tipo de aqüífero, pode sofrer constante recarga (como de chuvas e corpos de água), bem como interferência direta e indireta das ações do homem.

A dinâmica do movimento da água subterrânea é explicada pela Lei de Darcy, e dada pela Equação 1, que em síntese explica que seu movimento ocorre pela existência de diferença de cargas hidráulicas no aquíffero e pela capacidade do material rochoso de conduzir o fluido - água no caso (condutividade hidráulica).

$\mathrm{v}=\mathrm{K} \cdot(\mathrm{dh} / \mathrm{dl}) / \eta \mathrm{e}$

sendo: $\mathrm{v}=$ velocidade linear média $(\mathrm{L} / \mathrm{T}) ; \mathrm{K}=$ condutividade hidráulica $(\mathrm{L} / \mathrm{T}) ; \eta \mathrm{e}=$ porosidade efetiva $(\%)$, definida como porosidade da rocha por onde o fluido passa.

A dinâmica deste movimento definirá áreas de recarga e descarga. A Figura 1 apresenta todas as relações que a água subterrânea sofre com os outros sistemas, como os processos de recarga (precipitação, infiltração e drenagem gravitacional), de descarga (fluxo de sub-superfície, escoamento básico e escoamento submarino) e processos que interferem nesta dinâmica (evapotranspiração, movimento ascendente de vapor, capilaridade).

A dinâmica também é intrinsecamente relacionada às características geológicas do aqüífero e aos sistemas de fluxo (local, intermediário ou regional). O aquíf́ero freático é um exemplo de sistema de fluxo local, em que a área de recarga é toda a superfície do terreno não impermeabilizado e a descarga, ribeirões e rios locais.

A composição físico-química da água subterrânea é o produto resultante do enriquecimento mineral de águas provenientes do ciclo hidrológico (ar, superfície e solo) e de seu tempo de residência na rocha hospedeira (aqüífero). As diferentes composições das rochas hospedeiras e dos processos de mineralização resultam na diversidade composicional das águas subterrâneas.

As características gerais da composição físico-química das águas subterrâneas e de suas especificidades, de acordo com as características composicionais da rocha aquífera, são básicas para os estudos da qualidade e contaminação, pois fornecem as condições iniciais e ambientais do aqüífero.

\section{Poluição das águas subterrâneas}

A preocupação a respeito da poluição das águas subterrânea é recente e restrita em nosso país, uma vez que o usuário do recurso subterrâneo, particular ou governamental, ainda desconhece sua importância e ignora as graves conseqüências de sua contaminação ${ }^{11}$. Uma justificativa para esse fato é que ao contrário da contaminação das águas superficiais, identificada na maioria das vezes, a contaminação das águas subterrâneas não é visível e sua explora- ção é muito distribuída, dificultando assim a identificação do problema. A ação protetora ou de interrupção é aplicada tardiamente, além de que quando a contaminação se torna perceptível, geralmente já atingiu uma larga extensão ${ }^{12}$.

Como a recarga das águas no subsolo ocorre, na maioria dos casos, devido à infiltração da água de chuva em excesso no solo, atividades realizadas neste solo podem ameaçar a qualidade da água subterrânea. A poluição de aqüíferos ocorre onde o descarte da carga contaminante gerada pela atividade antrópica (urbana, industrial, agrícola, mineradora) é inadequadamente controlada e certos componentes excedem a capacidade de atenuação das camadas do solo ${ }^{13}$.

Em uma análise das atividades do homem que podem gerar uma carga contaminante no subsolo é importante reconhecer quais fontes são de emissão pontual e quais são de emissão difusa. Da mesma forma, devem ser distinguidas atividades onde a geração de carga é parte integral do sistema daquelas onde estão envolvidos componentes acidentais e incidentais, sobretudo considerando-se a prevenção e o controle de contaminação. A Tabela 1 apresenta um resumo dessas atividades, assinalando aquelas de maior probabilidade de ocorrência.

As fontes de poluição pontual são normalmente mais fáceis de serem identificadas, pois causam plumas de contaminação mais concentradas e mais definidas. Entretanto, quando essas atividades são pequenas e múltiplas podem se apresentar, essencialmente, como fontes difusas, com conseqüente dificuldade de identificação e controle. As fontes de poluição difusa geralmente não apresentam plumas de contaminação definidas, mas impactam uma área muito mais larga e, assim, maior volume do aquífero ${ }^{13}$.

Embora exista preocupação com a poluição das águas subterrâneas principalmente em aquíferos não confinados ou freáticos, sobretudo em lugares onde a zona não-saturada é delgada e o lençol freático é pouco profundo, os perfis naturais do solo podem atenuar ativamente, embora nem todos, os poluentes. Assim, os processos lentos de poluição de aqüíferos podem ser devido a vários fatores, entre eles ${ }^{12}$ : ação da filtração mecânica - ação exercida sobre as partículas em suspensão, tais como areia, argila, algas, microorganismos, sendo muito pequena ou quase inexistente em aquíf́eros permeáveis devido à existência de grandes fendas ou canais de dissolução; ação das reações de óxido-redução - os processos de oxidação são muito importantes na diminuição da contaminação por produtos orgânicos e nitrogenados, ocorrendo predominantemente durante a infiltração no meio nãosaturado, ainda que possam ser realizados no meio saturado. As bactérias e outros microorganismos presentes no terreno são fatores importantes para os fenômenos de oxidação e redução. A redução anaeróbica diminui um tipo de contaminação, mas pode resultar em outro de mesma intensidade ou maior, considerando-se que o produto de degradação e/ou transformação formado pode ser mais tóxico que a substância inicial; adsorção e absorção pelo terreno - a retenção supõe maior tempo de permanência no solo, o que permite que outros processos, como de oxidação e ação bacteriana, ocorram com maior intensidade. É importante considerar que o solo apresenta capacidade limitada de retenção; processos bioquímicos - estão estritamente ligados aos de óxido-redução; processos de precipitação e co-precipitação - afetam principalmente os metais; troca de gases - liberação de gases provenientes de processos anaeróbicos ou aeróbicos com entrada de oxigênio, ocorrendo principalmente no meio não-saturado e onde há camadas permeáveis; desintegração radioativa - forma natural de eliminação de substâncias radioativas; processo de diluição - a dispersão da água contaminada no aqüífero supõe certo grau de mistura. Quando existem bombeamentos, as próprias captações intervem de forma importante no processo de mistura, sendo que as captações ocorrem simultaneamente em diferentes níveis. 
Tabela 1. Atividades antrópicas potencialmente geradoras de carga contaminante ao aqüífero. Adaptada da ref. 13

\begin{tabular}{cc}
\hline Atividade & $\begin{array}{c}\text { Característica da } \\
\text { carga contaminante }\end{array}$ \\
\cline { 2 - 3 } & $\begin{array}{c}\text { distribuição principal } \\
\text { contaminante }\end{array}$ \\
\hline
\end{tabular}

\section{URBANA}

Saneamento "in situ"

Vazamento de esgotos (a)

Lagoas de oxidação (a)

Aplicação de águas residuais

em superfície (a)

Rios e canais de recepção (a)

Lixiviado de lixões/aterros sanitários

Tanques de combustível

Drenos de rodovias

\section{INDÚSTRIA}

Vazamento de tanques/tubos (b)

Derramamento acidental

Lagoas de efluentes

Lançamento de efluentes em superfície

Canais e rios receptores

Lixiviado de resíduos sólidos

Drenos de pátios

Material em suspensão e gases

AGRÍCOLA (c)

a. Área de cultivo

- com agroquímicos

- com irrigação

- com lodos/resíduos

- com irrigação de águas residuais

b. Beneficiamento/criação de gado e animais

- lagoas de efluentes sem revestimento

- lançamento em superfície

- canais e rios receptores de efluentes

\section{EXTRAÇÃO MINERAL}

\section{Desmonte hidráulico}

Descarga de água de drenagem

Lagoa de decantação

Lixiviado de resíduos sólidos

$\begin{array}{cc}\text { u/r P-D } & \text { n f o } \\ \text { u P-L } & \text { of n } \\ \text { u/r P } & \text { of n } \\ \text { u/r P-D } & \text { n s o f } \\ \text { u/r P-L } & \text { n o f } \\ \text { u/r P } & \text { o s m } \\ \text { u/r P-D } & \text { o } \\ \text { u/r P-D } & \text { s o } \\ & \\ \text { u P-D } & \text { o m } \\ \text { u P-D } & \text { o m } \\ \text { u P } & \text { o m s } \\ \text { u P-D } & \text { o m s } \\ \text { u P-L } & \text { o m s } \\ \text { u/r P } & \text { o m s } \\ \text { u/r P } & \text { o m } \\ \text { u/r D } & \text { s o }\end{array}$

$\begin{array}{ll}\text { r D } & \text { no } \\ \text { r D } & \text { nos } \\ \text { r D } & \text { nos } \\ \text { r D } & \text { nos f }\end{array}$

$\begin{array}{cc}\text { r P } & \text { fo n } \\ \text { r P-D } & \text { n s of } \\ \text { r P-L } & \text { on f }\end{array}$

$\begin{array}{cc}\text { r/u P-D } & \text { s m } \\ \text { r/u P-D } & \text { m s } \\ \text { r/u P } & \text { m s } \\ \text { r/u P } & \text { s m }\end{array}$

(a) Pode incluir componentes industriais; (b) Pode também ocorrer em áreas não industriais; (c) Intensificação apresenta aumento no risco de contaminação; $\mathrm{u} / \mathrm{r}=$ Urbano/Rural; P/L/D/R = Pontual/Linear/ Difuso/Regional; $\mathrm{n}=$ Nutrientes; $\mathrm{f}=$ Patógenos fecais; $\mathrm{o}=$ Compostos orgânicos sintéticos e/ou carga orgânica; $\mathrm{s}=$ Salinidade; $\mathrm{m}=$ Metais.

A zona não-saturada é de especial importância não apenas por representar a primeira linha de defesa natural contra a poluição, mas também por possuir um ambiente favorável para a atenuação e eliminação de poluentes (Figura 3).

A maioria dos processos que causam atenuação e eliminação de contaminantes no subsolo são mais ativos na zona do solo biologicamente ativa, como resultado de seu maior conteúdo de argila e matéria orgânica e da sua população bacteriana ${ }^{15}$.

Cada um dos processos descritos anteriormente continuará atuando na zona saturada, mas geralmente em taxas menores. Nessa zona, a redução das concentrações dos poluentes dependerá principalmente da diluição, resultado da dispersão hidrodinâmica, que acompanha o fluxo da água subterrânea. Contudo, a zona não-saturada pode ser complexa e sua capacidade de atenuação dos poluentes,

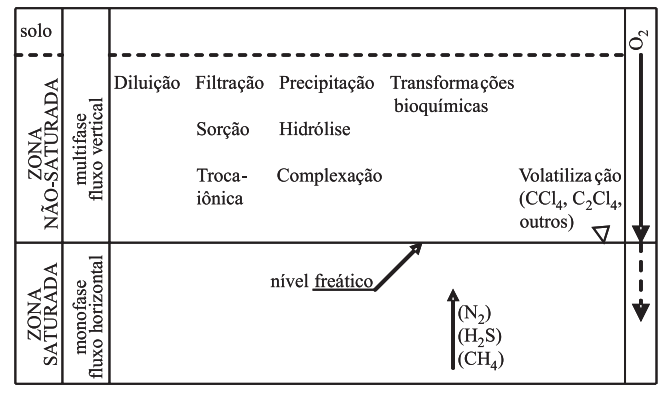

Figura 3. Processos que induzem a atenuação de poluentes nos sistemas de água subterrânea. Adaptada da ref. 14

difícil de predizer. No caso de poluentes persistentes e móveis, a zona não-saturada poderá apenas induzir um atraso no tempo de chegada à água subterrânea, sem atenuação benéfica alguma ${ }^{14}$.

\section{Poluição das águas subterrâneas por atividades agrícolas}

O cultivo e manejo do solo exercem grande influência na qualidade das águas subterrâneas e nas taxas de recarga de alguns aquiíferos. Algumas práticas agrícolas são capazes de causar contaminação difusa por nutrientes e pesticidas, especialmente em áreas com solos pouco espessos com boa drenagem, e ocasionar um aumento da salinidade das águas, especialmente em regiões mais áridas ${ }^{15}$.

Os tipos de atividade agrícola que geram contaminação difusa mais preocupante das águas subterrâneas são as relacionadas com extensas áreas de monocultura. Práticas agrícolas envolvendo o cultivo de culturas perenes apresentam menor perda por lixiviação que em locais onde as plantações sazonais são praticadas, devido ao menor distúrbio e aeração do solo e também ao aumento da demanda de nutrientes pelas plantas ${ }^{16}$.

O impacto das atividades agrícolas modernas sobre a qualidade das águas subterrâneas tornou-se conhecido em alguns países industrializados durante a década de 1970, entretanto estava restrito ao uso de fertilizantes, principalmente compostos nitrogenados ${ }^{14}$.

Um outro fator preocupante é o efluente principal da indústria do álcool, a vinhaça. A vinhaça ou vinhoto possui altas concentrações de potássio, cloreto, nitrogênio total, cálcio, sulfato, fósforo total, concentração significativa de alguns metais e demanda bioquímica de oxigênio (DBO) elevada que pode causar sérios danos aos cursos superficiais de água. Devido a esse problema, optou-se pela disposição da vinhaça no solo, por aspersão ou irrigação por canais, como fertilizante. A vinhaça também é disposta em lagoas e valas de infiltração. Tais áreas são conhecidas como "áreas de sacrifício". Ambas as práticas representam uma ameaça local à qualidade da água subterrânea. Embora estudos demonstrem a atenuação do solo sobre os principais indicadores de poluição (nitrogênio, carga orgânica) é necessário continuar com tais estudos por tempo prolongado e realizá-los em solos mais permeáveis, antes de se chegar a uma conclusão final ${ }^{17}$.

Recentemente, uma Decisão de Diretoria da Cetesb (Companhia de Tecnologia de Saneamento Ambiental do Estado de São Paulo) (Decisão de Diretoria 35, de 09/31 de 2005) homologou a Norma Técnica P4.231 - Vinhaça - Critérios e Procedimentos para aplicação no solo agrícola ${ }^{18}$. Esta norma apresenta como objetivo dispor sobre os critérios e procedimentos para a aplicação da vinhaça, gerada pela atividade sucroalcooleira no processamento de cana-de-açúcar, no solo do Estado de São Paulo. A norma suspende, imediatamente, a prática de armazenamento e/ou disposição de vinhaça ou lodo em áreas de sacrifício, eliminando-se aquelas que ainda estão sendo utilizadas nas unidades produtoras. Outra consideração é sobre a impermeabilização dos canais mestres ou primários de uso 
permanente para distribuição de vinhaça durante o período da safra, que deverá ser feita com geomembrana impermeabilizante ou outra técnica de efeito igual ou superior. A decisão apresenta uma equação para cálculo da dosagem de vinhaça a ser aplicada para enriquecimento do solo agrícola. $\mathrm{O}$ cálculo considera a profundidade e a fertilidade do solo, a concentração de potássio na vinhaça e a extração média desse elemento pela cultura.

A atividade agrícola, especialmente o uso de pesticidas, é considerada uma das atividades mais difíceis de ser avaliada, uma vez que o comportamento dos diversos pesticidas utilizados é ainda pouco conhecido em subsuperfície e sua aplicação é ampla e efetuada em baixas concentrações. Embora a maior preocupação devido a essa atividade seja a contaminação por fertilizantes inorgânicos, nitrato principalmente, a literatura tem apresentado trabalhos que relatam a presença de diversas classes de pesticidas em água subterrânea ${ }^{19-21}$. Sendo assim, mais atenção deve ser destinada a essas substâncias que são utilizadas em larga escala na agricultura ${ }^{11}$.

\section{Poluição de águas subterrâneas por pesticidas}

Os recursos hídricos agem como integradores dos processos biogeoquímicos de qualquer região. Sendo assim, quando pesticidas são introduzidos, os recursos hídricos, sejam superficiais ou subterrâneos, aparecem como o destino final principal dos pesticidas. Solo e água atuam interativamente e qualquer ação que cause efeito adverso em um destes elementos afetará o outro ${ }^{22}$. É importante ressaltar que, em alguns casos, menos de $0,1 \%$ da quantidade de pesticidas aplicados alcançam a peste alvo, enquanto o restante $(99,9 \%)$ tem potencial para se mover para outros compartimentos ambientais, como as águas superficiais e subterrâneas ${ }^{5}$.

$\mathrm{O}$ processo natural que governa a velocidade e o transporte de pesticidas no ambiente pode ser agrupado nas seguintes categorias: lixiviação, volatilização, degradação, sorção e absorção pelas plantas (Figura 4). A absorção pela planta é geralmente o menor componente. A perda por volatilização ocorre a partir das partículas do solo, da planta e da umidade do solo. Os pesticidas podem ser degradados no solo por processos microbiológicos ou químicos, produzindo metabólitos e compostos mais simples, como amônia e dióxido de carbono ${ }^{23}$.

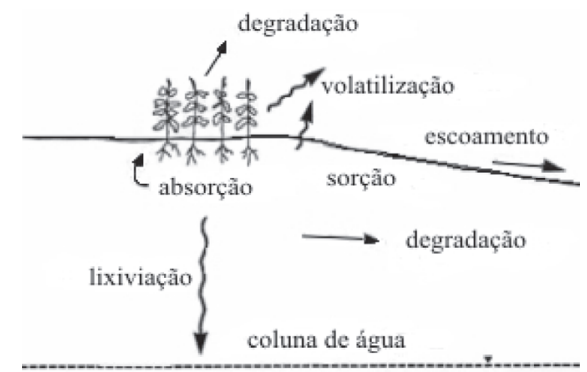

Figura 4. Processos determinantes da velocidade de pesticidas no solo e na zona não-saturada. Adaptada da ref. 23

Vários fatores estão relacionados com a interação de pesticidas com os constituintes do solo. Estrutura molecular, textura do solo, acidez, temperatura, solubilidade e hidrofobicidade da matéria orgânica são alguns dos fatores mais importantes que influenciam a adsorção de uma substância. A adsorção rege os mecanismos de biodisponibilidade e movimentação dos pesticidas nos solos e está diretamente relacionada com o potencial de degradação e lixiviação de um poluente ${ }^{24}$.

Por muitos anos, a mobilidade dos pesticidas foi identificada como característica-chave na avaliação do potencial de lixiviação, exigindo o uso de mecanismos, como o coeficiente de sorção, para ordenar o potencial de mobilidade de pesticidas no solo. Entretanto, mobilidade por si só não constitui bom indicador de lixiviação e de potencial de contaminação de água subterrânea. A combinação mobilidade/persistência é que determina se o composto será degradado durante seu tempo de permanência na zona não-saturada do solo $^{25}$. Os primeiros experimentos sobre a investigação da persistência de pesticidas em solo foram realizados com o objetivo de avaliar a bioatividade dos mesmos, com a preocupação de evitar dano às plantas sensíveis ${ }^{26}$.

É importante ressaltar que o entendimento da poluição de águas subterrâneas por pesticidas requer o conhecimento da relação entre os seguintes fatores: uso e características do solo, clima, propriedades do aqüífero e propriedades intrínsecas do pesticida ${ }^{27}$.

\section{Avaliação da contaminação da água subterrânea por pesticidas}

A poluição das águas subterrâneas por pesticidas era um assunto pouco relevante até a década de 1980, sendo o íon nitrato considerado como o contaminante mais importante para o problema da poluição de águas subterrâneas relacionado com práticas agrícolas ${ }^{23}$.

$\mathrm{O}$ estudo de impacto por pesticidas ganhou interesse a partir de 1979, inspirado por descobertas de nematicidas em aquífferos de vários estados norte-americanos. A partir desse fato, muitos outros casos de contaminação de solo, recursos hídricos, animais e, mais crítico, de seres humanos por pesticidas foram diagnosticados nas regiões temperadas, mas pouco investigados em regiões tropicais ${ }^{22,28}$.

Em uma revisão da literatura nacional e internacional, Dores ${ }^{21}$ relata que pesticidas vêm sendo encontrados, mesmo que em baixas concentrações, em amostras de água subterrânea de diferentes países, tais como Grã-Bretanha, Alemanha, Estados Unidos, Grécia, Bulgária, Espanha, Portugal e Brasil.

A preocupação com a qualidade das águas superficial e subterrânea tem levado alguns países a lançarem programas que avaliem a qualidade das mesmas. O Programa Nacional de Avaliação da Qualidade da Água (NAWQA) do Serviço Geológico dos Estados Unidos (USGS) tem estudado mais de cinqüenta principais bacias e aqüíferos. Durante os anos de 1992 a 1998, os estudos incluíram análises de 76 pesticidas, dentre centenas atualmente registrados para uso, e 7 metabólitos em mais de 8000 amostras de águas de rios e poços nas áreas urbana e rural. Os resultados demonstraram que os pesticidas foram mais freqüentemente encontrados em poços rasos tanto na área urbana quanto rural. Embora na maioria dos poços, onde pesticidas foram detectados, as concentrações foram abaixo dos padrões de potabilidade da EPA ("Environmental Protection Agency"), cerca de $25 \%$ das amostras de poços nas áreas urbana e rural e cerca de $10 \%$ das amostras provenientes dos principais aquífferos apresentaram detecção de dois ou mais pesticidas ${ }^{29}$.

No Brasil, a Companhia de Tecnologia de Saneamento Ambiental do Estado de São Paulo (Cetesb) realiza desde 1990 monitoramentos dos principais aqüíferos do Estado. O último relatório apresentado, referente ao período de 2001 a 2003, aborda coletas e análises semestrais de 162 poços de monitoramento. Os parâmetros analisados foram baseados no padrão de potabilidade de água apresentado na Portaria 1469 de 29/12/2000 do Ministério da Saúde, atualizada pela Portaria 518 de 25/03/2004; entretanto as únicas substâncias orgânicas analisadas na região metropolitana de São Paulo foram: 1,2dicloroetano, tetracloroetileno, cloreto de vinila, clorofórmio e benzeno. Essas moléculas foram escolhidas com base nos valores orientadores para solo e água subterrânea para o Estado de São Paulo. Embora a lista dos valores orientadores demonstre preocupação com contaminantes orgânicos (benzeno, tolueno, xilenos, estireno, naftaleno, diclorobenzeno, hexaclorobenzeno, tetracloroetileno, tricloroetileno, 1,1,1-tricloroetano, 1,2-dicloroetano, cloreto de vinila, 
pentaclorofenol, triclorofenol, fenol, aldrin, dieldrin, DDT, endrin e lindano), somente pesticidas que tiveram seu uso proibido no Brasil são contemplados, não abordando assim os que apresentam registro para uso $^{30}$. Uma atualização dessa lista foi publicada pela Cetesb em novembro de 2005, apresentando a inclusão de diversos compostos orgânicos, mas somente DDD, DDE e $\beta$ - $\mathrm{HCH}$ foram inseridos na subdivisão dos pesticidas ${ }^{31}$.

Um trabalho interessante realizado no Brasil foi a avaliação da presença de um dos pesticidas utilizados em larga escala atualmente, tebutiurom, em amostras de água subterrânea de um poço semi-artesiano de $53 \mathrm{~m}$ de profundidade localizado na microbacia do Córrego Espraiado, município de Ribeirão Preto, localizada sobre a área de recarga do Aqüífero Guarani. O monitoramento, realizado entre 1995 e 1999, demonstrou que o tebutiurom estava presente em todas as amostras analisadas, embora em concentrações abaixo do nível crítico para padrão de potabilidade estabelecidos pela Comunidade Econômica Européia $\left(0,1 \mu \mathrm{g} \mathrm{L}^{-1}\right.$ por pesticida em uso e de $0,5 \mu \mathrm{g} \mathrm{L}^{-1}$ para pesticidas totais). Os autores alertam para o perigo de contaminação da água subterrânea pelo herbicida estudado, sendo que a concentração do mesmo pode aumentar devido à existência de condições ambientais favoráveis à preservação da molécula em profundidade, tais como baixa temperatura, baixa atividade biológica e ausência de luz ${ }^{20}$.

Monitoramento de pesticidas no ambiente é uma ferramenta importante para a caracterização e o gerenciamento dos riscos ambientais decorrentes do uso desses produtos em condições reais e pode fazer parte da avaliação no processo de registro de novos produtos ou da reavaliação de produtos em uso. Planos de monitoramento de risco ambiental de pesticidas podem cumprir seu papel desde que não sejam apenas uma coleção de dados, e sim um trabalho sistemático, dirigido por objetivos claros e factíveis. Buscam muito mais a ampliação da base de informações sobre o que ocorre com os pesticidas depois de aplicados no campo, suas concentrações nos diferentes compartimentos ambientais e os possíveis efeitos negativos. Entretanto, a experiência acumulada nos últimos anos tem mostrado que avaliações de impactos ambientais são muito complexas, caras e, por vezes, não podem ser levadas a efeito na sua plenitude por problemas operacionais ${ }^{6}$.

Uma alternativa ao monitoramento ambiental é a prevenção contra o perigo de poluição dos recursos hídricos subterrâneos ${ }^{32}$. Gooddy et $a l .{ }^{33}$ enfatizam a necessidade de compreensão mais detalhada do movimento e transporte dos pesticidas e de seus produtos de degradação em ambas as zonas do solo, não-saturada, onde o retardamento e degradação ocorrem, e na zona saturada, no aqüífero.

Neste sentido, a avaliação da mobilidade de pesticidas no solo pode envolver aproximações diretas ou indiretas. Estimativas diretas envolvem o estudo do comportamento do pesticida aplicado no solo. Já as estimativas indiretas são baseadas na medida de parâmetros que utilizam modelos para avaliação do potencial de lixiviação dos pesticidas ${ }^{34,35}$.

Esses modelos são representações físicas, conceituais ou matemáticas da realidade, apresentando diferentes propósitos, tais como triagem - estabelecimento de prioridades, regulamentação/exposição - avaliações quantitativas e estabelecimento de regulamentos, e pesquisa - diversos tipos de aplicação e requerem grande número de dados$^{2}$. Técnicas de triagem e índices para avaliação da lixiviação de pesticidas têm sido propostos como estágio inicial para indicar o potencial do impacto dessas substâncias no ambiente, podendo ser aplicados em avaliações de risco de contaminação da água subterrânea por pesticidas ${ }^{2,36,37}$. Essas técnicas contemplam, isoladamente ou em conjunto, parâmetros que influenciam no transporte da molécula de pesticida do solo para água subterrânea. Tais parâmetros são: propriedades do pesticida (solubilidade, pressão de vapor, coefici- ente de adsorção normalizado em relação ao teor de carbono orgânico do solo $\left(\mathrm{K}_{\mathrm{oc}}\right)$ e coeficiente de partição octanol/água $\left(\mathrm{K}_{\mathrm{ow}}\right)$ ), condições ambientais (clima, textura e conteúdo de água do solo), características da paisagem (topografia e presença de sistemas de drenagem e redes de entrada de escoamento de águas superficiais) e práticas de manejo (agricultura, seleção da cultura e método de aplicação do pesticida) $)^{3,5,38}$.

Em um trabalho recente, Lourencetti et al. ${ }^{39}$ comparam alguns métodos descritos na literatura - critérios de "screening" da EPA², índice de GUS ("Groundwater Ubiquity Score") nuação (AF) e Retardamento (RF) ${ }^{36}$, índice de LIX ("Screening Leachability indeX") ${ }^{41}$ e TLPI ("Temperature Leaching Potenctial Index") $)^{37}$ - para avaliação do potencial de lixiviação de pesticidas, apresentando os fatores considerados e as equações relacionadas na construção dos mesmos. A ausência de dados sobre os pesticidas e metabólitos e estudo de efeitos combinados (aditivos, sinérgicos ou antagônicos) são apontados como limitações desses métodos.

Incertezas inerentes aos modelos de representação do ambiente são enfatizadas por Cohen et al. ${ }^{2}$, pois diferentes locais apresentam variações no tipo de solo, clima, cultura e outros fatores que, em muitos casos, não são considerados pelos modelos. Freqüentemente, os valores das propriedades dos pesticidas são determinadas pelos fabricantes nos países onde os mesmos são desenvolvidos, sendo as condições ambientais, muitas vezes, distintas do local onde os modelos são aplicados ${ }^{42}$.

Embora os modelos não reflitam exatamente a realidade, os mesmos são ferramentas valiosas para avaliações simplificadas do comportamento dos pesticidas no ambiente ${ }^{2}$. Alguns modelos vêm sendo utilizados juntamente com sistemas de informações geográficas, em escala regional, para avaliar, de forma preliminar, a vulnerabilidade de contaminação da água subterrânea por fontes de poluição não pontuais, como os pesticidas ${ }^{43}$.

A investigação das estimativas diretas tem sido realizada estudando-se o comportamento dos pesticidas no solo, seja pelo estudo de lixiviação, sorção no solo e persistência (determinação do tempo de meia-vida no pesticida no solo $)^{44-49}$. Estes estudos podem ser realizados tanto em laboratório como em campo. O método mais satisfatório para avaliação da mobilidade relativa de um dado pesticida no solo é o que melhor se aproxima das condições reais, apresentando reprodutibilidade ${ }^{44}$. A Tabela 2 apresenta trabalhos que investigam a mobilidade de pesticidas no solo utilizando estudos de lixiviação, sorção e persistência dos pesticidas.

Os estudos de lixiviação têm sido realizados em laboratório com colunas de lixiviação de solo, desestruturado e não desestruturado, e com lisímetros, instalados em campo ou em laboratório (Tabela 2). Lisímetros são definidos como contêineres de solo representando o ambiente do campo, sendo utilizados dois tipos básicos: natural (perfil do solo) ou preenchido pela matriz (solo desestruturado) com drenagem livre ou controlada por succção ${ }^{42}$. Em estudos deste tipo, as concentrações dos pesticidas são determinadas no lixiviado durante o experimento e nas diferentes camadas do solo, no final do experimento ${ }^{49}$. Embora a maioria dos estudos seja realizada em laboratório, as colunas de solo, desestruturadas e não desestruturadas, podem ser mantidas sob condições naturais (temperatura, pluviosidade, radiação solar).

Estudos de laboratório são frequientemente apontados como não adequados para avaliar o risco de contaminação das águas subterrâneas por pesticidas. A avaliação da persistência e mobilidade de pesticidas em solo pode ser influenciada pelas condições climáticas variáveis e processos como volatilização, fotólise, lixiviação e transporte de fluxo preferencial, quando comparado com condições naturais ${ }^{53}$. A investigação da dissipação de pesticidas em laboratório é geralmente conduzida sobre condições controladas, como temperatura, luz e umidade, e freqüentemente busca o estu- 
do de processos isolados como, por ex., biodegradação ou fotólise ${ }^{34}$. Estudos de laboratório são considerados importantes, sendo muitas vezes realizados em conjunto com estudos de campo e apontados como necessários para o entendimento de parâmetros ambientais responsáveis por efeitos simples ${ }^{42}$.

As investigações do destino de pesticidas em campo são conduzidas sobre condições naturais, sendo realizadas para elucidar o comportamento de um composto em um ambiente onde múltiplas forças de dispersão e transporte atuam simultaneamente. A grande desvantagem de estudos em campo é a elevada variabilidade dos resultados obtidos para o mesmo composto em diferentes locais ou no mesmo local em diferentes $\operatorname{anos}^{34}$.

Os processos de adsorção e dessorção (sorção), que ocorrem entre os pesticidas e as partículas do solo, são dois dos fatores que regulam a lixiviação dos pesticidas e, conseqüentemente, a contaminação das águas superficiais e subterrâneas. Esses processos variam conforme as características dos pesticidas e do solo, influenciando ainda na atividade biológica, persistência e mobilidade ${ }^{54}$. Estudos de sorção (adsorção/dessorção) fornecem valores dos coeficientes de distribuição do pesticida entre as partículas e a solução do solo (Kd). Esses valores são específicos para uma determinada molécula, sendo normalmente relacionados com as propriedades do solo testado. A partir do Kd e da matéria orgânica do solo obtém-se o coeficiente de adsorção normalizado em relação ao teor de carbono orgânico do solo $(\mathrm{Koc})^{55}$.

A matéria orgânica é apontada como um dos principais fatores que afetam a sorção e, conseqüentemente, a lixiviação de pesticidas $^{32}$. A aplicação de fertilizantes orgânicos, como esterco, lodo, resíduos sólidos urbanos e vinhaça, é uma prática comum na agricultura brasileira. Geralmente a adição de matéria orgânica aumenta a adsorção de pesticidas e diminui sua mobilidade no perfil do solo. Entretanto, a aplicação de carbono orgânico pode resultar em aumento da mobilidade de pesticidas, devido ao aumento do conteúdo de carbono orgânico dissolvido na solução do solo que complexa com os pesticidas, servindo como um veículo para transporte dos mesmos para camadas mais profundas do $\mathrm{solo}^{47}$.

Prata et al. ${ }^{56}$ ao avaliarem os efeitos da adição de vinhaça nos processos de degradação e adsorção dos herbicidas diuron e ametrina no solo, verificaram que a degradação dos dois herbicidas foi maior para um dos solos tratados com vinhaça. A adição da vinhaça não influenciou na adsorção das duas substâncias no solo, sendo o estudo de sorção realizado pelo teste de equilíbrio padrão. Entretanto, devido às diferentes propriedades dos diversos princípios ativos em uso, este resultado não pode ser generalizado para todos os pesticidas.

Estudos que avaliam a mobilidade dos pesticidas no solo, tais como, lixiviação, sorção e degradação, em laboratório ou em condições de campo, geralmente resultam em informações sobre as propriedades físico-químicas dos pesticidas o mais próximo possível da realidade. Essas propriedades podem ser utilizadas na aplicação de $\operatorname{modelos}^{2}$ para avaliação preliminar do potencial de contaminação de águas superficiais e subterrâneas por pesticidas.

\section{CONSIDERAÇÕES FINAIS}

Considerando a crescente importância da água subterrânea para abastecimento público e o fato dos pesticidas representarem uma fonte de contaminação difusa dessa matriz, a avaliação da qualidade das águas subterrâneas é um tema que merece investigações sistemáticas e a longo prazo. Estudos de monitoramento ambiental são realizados com esse intuito e quando resultam em dados que ultrapassam os limites máximos para resíduos de pesticidas, práticas de remediação são recomendadas. Entretanto, os elevados custos dessas práticas não são sempre proporcionais à sua eficiência. Assim, avaliações preliminares podem ser realizadas antes que os pesticidas, realmente empregados, atinjam as águas subterrâneas. Tais avaliações podem ser efetuadas seja pelo uso de modelos matemáticos ou

Tabela 2. Estudos abordando a mobilidade de pesticidas no solo

\begin{tabular}{|c|c|c|c|c|}
\hline Pesticida & Tipo de estudo & Detecção & Observações & Ref. \\
\hline Endosulfam & $\begin{array}{l}\text { Lixiviação (coluna de solo desestruturado: } 40 \\
\text { x } 5 \mathrm{~cm} \text { ) (Laboratório) }\end{array}$ & Cintilização Líquida & & 50 \\
\hline Acetocloro & $\begin{array}{l}\text { Lixiviação (coluna de solo não desestruturado: } \\
20 \times 0,05 \mathrm{~cm} \text { ) (Laboratório) }\end{array}$ & Bioensaio (trigo) & $\begin{array}{l}\text { Semeadura direta e preparo } \\
\text { convencional }\end{array}$ & 46 \\
\hline Tebutiurom & Persistência (tempo de meia-vida) (Campo) & Bioensaio (aveia) & & 26 \\
\hline $\begin{array}{l}\text { Atrazina, diurom, tebutiurom, } \\
\text { bromacil, butidazol, prometom }\end{array}$ & Lixiviação (coluna: 30,5 x 9,7) (Laboratório) & Cintilização Líquida & Solo saturado e não-saturado & 44 \\
\hline Tebutiurom e diurom & $\begin{array}{l}\text { Lixiviação (coluna de solo não desestruturado: } \\
55 \times 15 \mathrm{~cm} \text {, lisímetro) (Laboratório) }\end{array}$ & HPLC-UV & Condições naturais & 48 \\
\hline Diurom e metabólitos, arizalim & $\begin{array}{l}\text { Lixiviação (coluna de solo não desestruturado: } \\
20 \times 15 \mathrm{~cm} \text {, lisímetro) (Laboratório) }\end{array}$ & HPLC-UV & Simulação da chuva & 49 \\
\hline Diurom e metabólitos & Diferentes camadas do solo (Campo) & HPLC-UV & $\begin{array}{l}\text { Análise de água subterrânea } \\
\text { da mesma área estudada }\end{array}$ & 33 \\
\hline $\begin{array}{l}\text { Hexazinona, sulfumetrom metil, } \\
\text { tebutiurom }\end{array}$ & $\begin{array}{l}\text { Lixiviação (coluna de solo não desestruturado: } \\
15 \times 150 \mathrm{~cm} \text {, lisímetro) (Laboratório) }\end{array}$ & Cintilização Líquida & $\begin{array}{l}\text { Água de chuva acidificada, } \\
\text { pH } 5,4 \text { ou } 4,2\end{array}$ & 51 \\
\hline Metalocloro & $\begin{array}{l}\text { Sorção, lixiviação (coluna de solo desestru- } \\
\text { turado: } 30 \times 6 \mathrm{~cm} \text { ) (Laboratório) }\end{array}$ & GC-ECD & Influência de adubo orgânico & 47 \\
\hline 2,4-D, $\beta$-ciclodextrim & $\begin{array}{l}\text { Lixiviação (coluna de solo não desestruturado: } \\
10 \times 5 \mathrm{~cm} \text { ) (Laboratório) }\end{array}$ & UV & $\begin{array}{l}\text { Influência do } \beta \text {-ciclodextrim } \\
\text { na adsorção do } 2,4-\mathrm{D}\end{array}$ & 52 \\
\hline Azinfos-metil & $\begin{array}{l}\text { Sorção e lixiviação (coluna de solo não } \\
\text { desestruturado: } 150 \text { x } 10 \mathrm{~mm} \text { ) (Laboratório) }\end{array}$ & HPLC-UV & & 32 \\
\hline $\begin{array}{l}\text { Atrazina, simazina, mono- } \\
\text { crotofós, trifluralina, metalo- } \\
\text { clor, cloriprofos, endosulfam, } \\
\lambda \text {-ciclotrim }\end{array}$ & $\begin{array}{l}\text { Lixiviação, persistência, sorção (lisímetro) } \\
\text { (Campo) }\end{array}$ & GC-MS & & 45 \\
\hline
\end{tabular}


pela avaliação da mobilidade dos pesticidas no solo. Os resultados desses estudos podem ser utilizados para alertar sobre o potencial de mobilidade dos pesticidas e possibilidade de contaminação das águas subterrâneas, fornecendo subsídios para planejamento e implantação de políticas públicas pelos órgãos governamentais.

O conhecimento brasileiro sobre os impactos na qualidade da água subterrânea encontra-se ainda em estágio inicial quando comparado com países como Estados Unidos, Canadá ou Alemanha. A identificação de áreas potencialmente contaminadas ainda é incipiente em nosso país, decorrente de uma histórica falta de políticas públicas para a gestão de águas subterrâneas acoplada ao desconhecimento da população e do governo sobre a importância dos aqüíferos para o abastecimento público.

\section{REFERÊNCIAS}

1. Filizola, H. F.; Ferracini, V. L.; Sans, L. M. A.; Gomes, M. A. F.; Ferreira, C. J. A.; Pesq. Agrop. Bras. 2002, 37, 659.

2. Cohen, S. Z.; Wauchope, R. D.; Klein, A. W.; Eadsforth, C. V.; Graney, R.; Pure Appl. Chem. 1995, 67, 2109.

3. Albanis, T. A.; Hela, D. G.; Sakellarides, T. M.; Konstantinou, I. K.; J. Chromatogr., A 1998, 823, 59.

4. Azevedo, D. A.; Lacorte, S.; Vinhas, T.; Viana, P.; Barceló, D.; J. Chromatogr., A 2000, 879, 13.

5. Sabik, H.; Jeannot, R.; Rondeau, B.; J. Chromatogr., A 2000, 885, 217.

6. Spadotto, C. A.; Gomes, M. A. F.; Luchini, L. C.; Andréa, M. M.; Monitoramento do risco ambiental de agrotóxivos: princípios e recomendações, Embrapa Meio Ambiente: Jaguariúna, 2004.

7. Domenico, P. A.; Schwartz, F. W.; Physical and Chemical Hydrogeology, $2^{\text {nd }}$ ed., John Wiley: New York, 1998.

8. Feitosa, F. A. C.; Manoel Filho, J.; Hidrogeologia: conceitos e aplicações, $2^{\text {nd }}$ ed., CPRM, UFP, LABHID: Fortaleza, 2000.

9. Fetter, C.W.; Applied Hydrogeology, $4^{\text {th }}$ ed., Prentice Hall: New York, 2001.

10. Pinto, N. L. S.; Hidrologia Básica, Ed. Blucher: São Paulo, 1980.

11. Hirata, R. C. A.; Rev. IG 1993, 14, 39

12. Custodio, E.; Llamas, M. R.; Hidrologia Subterrânea, $2^{\text {nd }}$ ed., Ediciones Omega: Barcelona, 1996.

13. Foster, S.; Hirata, R.; Gomes, D.; D'edlia, M.; Paris, M.; Groundwater Quality Protection: a guide for water utilities, municipal authorities, and environment agencies, The World Bank: Washington, 2002.

14. Foster, S.; Ventura, M.; Hirata, R.; Poluição das águas subterrâneas, Instituto Geológico: São Paulo, 1993.

15. Foster, S.; Hirata, R.; Determinación del riesgo de contaminación de aguas subterraneas, una metodologia basada en datos existents, Centro Panamericano de Ingenieria Sanitária y Ciências del Ambiente-Cepis: Lima, 1991.

16. Chilton, P. J.; Laurence, A. R.; Stuart, M. E. Em Groundwater Quality; Nash, H.; McCall, G. J., eds.; Champman \& Hall: London, 1996, cap. 3.

17. Freire, W. J.; Cortez, L. A. B.; Vinhaça de cana-de-açúcar, Agropecuária: Guaíba, 2000

18. http://www.orplana.com.br/corpo_legislacao_orplana_24.asp, acessada em Abril 2005.

19. Adamski, J.; Pugh, A. L.; Water Resour. Bull. 1996, 32, 97.

20. Gomes, M. A. F.; Spadotto, C. A.; Lanchotte, V. L.; Pesticidas: Rev. Ecotox. Meio Amb. 2001, 11, 65
21. Dores, E. F. G. C.; Tese de Doutorado, Universidade Estadual Paulista, Brasil, 2004.

22. Mattos, L. M.; Silva, E. F.; Pesticidas: Rev. Ecotox. Meio Amb. 1999, 9, 103.

23. Chilton, P. J.; Laurence, A. R.; Stuart, M. E. P. Em Groundwater Contaminants and their migration; Mather, J.; Banks, D.; Dumpleton, S.; Fermor, M., eds.; The Geological Society: London, 1998.

24. Dores, E. F. G. C.; De-Lamonica-Freire, E. M.; Pesticidas: Rev. Ecotox. Meio Amb. 1999, 9, 1.

25. Spadotto, C. A.; Filizola, H.; Gomes, M. A.; Pesticidas: Revista Ecotox. Meio Amb. 2001, 11, 127.

26. Blanco, H. G.; Oliveira, D. A.; Pesq. Agrop. Bras. 1989, 24, 1161.

27. Worrall, F.; Kolpin, D. W.; J. Hydrology 2004, 293, 191.

28. Racke, K. D.; Pure Appl. Chem. 2003, 75, 1905.

29. Giliom, R. J.; Hydrological Processes 2001, 15, 3197.

30. http://www.cetesb.sp.gov.br/Agua/agua_geral.asp, acessada em Julho 2004.

31. http://www.cetesb.sp.gov.br/Solo/relatorios/tabela_valores_2005.pdf, acessada em Fevereiro 2006

32. Farran, A.; Chentouf, A.; J. Chromatogr., A 2000, 869, 481.

33. Gooddy, D. C.; Chilton, P. J.; Harrison, I.; Sci. Total Environ. 2002, 297, 67.

34. Racke, K. D.; Skidmore, M. W.; Hamilton, D. J.; Unsworth, J. B.; Miyamoto, J.; Cohen, S. Z.; Pure Appl. Chem 1997, 69, 1349.

35. Oliveira Jr, R. S.; Koshinen, W. C.; Ferreira, F. A.; Weed Res. 2001, 41, 97.

36. Rao, P. S. C.; Hornsby, A. G.; Jessup, R. E.; Soil Crop Sci. Soc. Florida 1985, 44, 1 .

37. Paraíba, L. C.; Cerdeira, A. L.; Silva, E. F.; Martins, J. S.; Coutinho, H. L. C.; Chemosphere 2003, 53, 1087.

38. Martínez, R. C.; Gonzalo, E. R.; Laespada, M. E. F.; Román, F. J. S. S.; J. Chromatogr., A 2000, 869, 471.

39. Lourencetti, C.; Ribeiro, M. L.; Santiago-Silva, M.; Spadotto, C. A.; Pesticidas: Rev. Ecotox. Meio Amb. 2005, 15, 1.

40. Gustafson, D. I.; Environ Toxicol. Chem. 1989, 8, 339.

41. Spadotto, C. A.; Pesticidas: Rev. Ecotox. Meio Amb. 2002, 12, 2002.

42. Winton, K.; Weber, J. B.; Weed Technol. 1996, 10, 202.

43. Segura, J. E. S.; Loureiro, C. O.; Resumos do IX Congresso Brasileiro de Águas Subterrâneas, Salvador, Brasil, 1996.; Diaz-Diaz, R.; Loague, K. Environ. Toxicol. Chem. 2001, 20, 1958.; Hantush, M. M.; Mariño, M. A.; Islam, M. R.; J. Hydrology 2000, 227, 66

44. Weber, J. B.; Whitacre, D. M.; Weed Sci. 1982, $30,579$.

45. Laabs, V.; Amelung, W.; Pinto, A.; Altstaedt, A.; Zech, W.; Chemosphere 2000, 41, 1441

46. Ferri, M. V. W.; Vidal, R. A.; Fleck, N. G.; Cassol, E. A.; Gomes, P. A.; Pesticidas: Rev. Ecotox. Meio Amb. 2003, 13, 147.

47. Singh, N.; J. Environ. Qual. 2003, 32, 1743.

48. Matallo, M. B.; Luchini, L. C.; Gomes, M. A. F.; Spadotto, C. A.; Cerdeira, A. L.; Marin, G. C.; Pesticidas: Rev. Ecotox. Meio Amb. 2003, 13, 83.

49. Landrry, D.; Dousset, S.; Andreux, F.; Chemosphere 2004, 54, 735.

50. Tornisielo, V. L.; Pinho, R. S.; Monteiro, R. T. R.; Costa, M. A.; Pesticidas: Rev. Ecotox. Meio Amb. 1998, 8, 1.

51. Stone, D. M.; Harris, A. R.; Koskinen, W. C.; Environ. Toxicol. Chem. 1993, 12,399 .

52. Morillo, E.; Perez-Martinez, J. I.; Gines, J. M.; Chemosphere 2001, 44, 1065.

53. Laabs, V.; Amelung, W.; Pinto, A.; Zech, W. J. Environ. Qual. 2000, 31, 256.

54. Souza, M. D.; Boeira, R. C.; Gomes, M. A. F.; Pesticidas: Rev. Ecotox. e Meio Amb. 2000, 10, 113 .

55. Weber, J. B.; Wilkerson, G. G.; Reinhardt, C. F.; Chemosphere 2004, 55, 157

56. Prata, F.; Lavorenti, A.; Regitano, J. B.; Tornisielo, V. L.; Rev. Bras. Ciên. Solo 2000, 24, 217; Prata, F.; Lavorenti, A.; Regitano, J. B.; Tornisielo, V. L.; Pesq. Agrop. Bras. 2001, 36, 975. 